\title{
Formic Acid Oxidation Catalytic Properties of Pd Nanoclusters Prepared by Physical Vapor Deposition
}

\author{
Cheng-Wei LIN ${ }^{1}$, Qing LUO ${ }^{1}$, Meng LEI ${ }^{1}$, \\ Lai-Sen WANG ${ }^{1, a,{ }^{\star}}$, Dong-Liang PENG ${ }^{1, b^{\star}}$ \\ ${ }^{1}$ Department of Materials Science and Engineering, Collaborative Innovation Center of Chemistry \\ for Energy Materials, College of Materials, Xiamen University, Xiamen 361005, P. R. China \\ *Corresponding author: awangls@xmu.edu.cn, ${ }^{b}$ dlpeng@xmu.edu.cn
}

Keywords: Plasma gas-phase deposition technology, Pd nanoclusters, Formic acid oxidation, Electrocatalytic activity

\begin{abstract}
A series of narrow size distribution nanocluster-assembled Pd films with ultraclean surfaces have been synthesized by plasma-gas-condensation cluster deposition system at different substrate temperatures. The electrocatalytic oxidation of formic acid on nanoclusters-assembled Pd film were studied. Cyclic voltammetry and chronoamperometry tests revealed that Pd nanoclusters assembled film have outstanding electrocatalytic activities, including large electrochemical surface area, high current density peak of formic acid oxidation and considerable stability. Moreover, the substrate temperature was found to have an important influence to their catalytic activities.
\end{abstract}

\section{Introduction}

Nowadays, in order to solve the energy issue, a lot of work has been made to study the direct formic acid fuel cell (DFAFC) and its catalysts which played a crucial role in the DFAFC performance [1]. It is well known that Pt has been employed as one of the most important catalysts for many years. Because of its expensive price, relatively slow reaction rate and the intermediate carbon monoxide (CO) poisoning [2, 3], Pt has been seriously limited narrow application field. Compared to Pt, the recent research indicated that Pd catalysts in nanoscale showed better catalysis of formic acid oxidation (FAO) and more resistance to CO poisoning [4].

There are various methods that have been used to synthesize the monodisperse Pd nanoclusters (NCs), in which the liquid-phase method was the most commonly used one [5-8]. However, there are several limitations. For example, 1) it was difficult to control and obtain Pd NCs with narrow size and shape distributions; 2) the catalytic activities were limited seriously by the surfactants which were used to prevent Pd NCs from conglomerating [9]; 3) the weak attachment between as-prepared catalyst and glassy carbon plate (GCP) was completed by pipetting-drying technology, so they needed to be covered with a thin Nafion film [10]. Besides, the thickness of catalyst layer is difficult to control uniformly, which easily leads to bad catalytic performance and repeatability. Fortunately, these problems are expected to be resolved by physical vapor deposition (PVD) which is different from traditional chemosynthesis. In the PVD synthesis, Pd NCs are synthesized under the high vacuum and inert gas condition in the plasma-gas-condensation clusters deposition apparatus, which protects them away from surface pollution and oxidation. On the other hand, the as-prepared samples were cluster-assembled Pd films whose packing density (P) was only about 30\% of bulk Pd [11], and had a narrow particles size distribution with an average size of $5.8 \mathrm{~nm}$. Besides, Pd NCs, directly deposited onto the GCP, have high adhesion strength and perfect contact between adjacent clusters even without additives. Above all, Pd catalysts prepared by PVD have many advantages including ultraclean surface, small size and porous stacks that can achieve more active sites, larger specific surface area (SSA) and effective contact area (ECA) in catalytic reaction, so as-synthesized Pd NCs catalysts show a appreciable utilization of Pd and a high catalytic activity.

Herein, a series of Pd NCs with narrow size distribution were prepared by a plasma-gascondensation nanocluster deposition system at substrate temperatures $\left(T_{s}\right)$ ranging from room temperature (RT) to $350{ }^{\circ} \mathrm{C}$, and their structure, electrocatalytic properties and morphology were 
investigated. The nanoclusters-assembled Pd films with outstanding electrocatalytic activities and good stability were observed.

\section{Experiment}

A series of Pd NCs were prepared by a plasma-gas-condensation clusters deposition system under different $T_{s}$ including RT, $200{ }^{\circ} \mathrm{C}, 250{ }^{\circ} \mathrm{C}, 300{ }^{\circ} \mathrm{C}$ and $350{ }^{\circ} \mathrm{C}$, and the sample names were labelled as $\mathrm{Pd}_{\mathrm{RT}}, \mathrm{Pd}_{200}, \mathrm{Pd}_{250}, \mathrm{Pd}_{300}$ and $\mathrm{Pd}_{350}$, respectively. In our previous paper, the process for the preparation of cluster-assembled films was precisely delineated (the schematic diagram is shown in Fig. 1) [12]. During deposition, a high-purity Pd (99.99 \%) metal target was used as the cluster source. Before deposition, the base pressure of the chamber was pumped below $4 \times 10^{-4} \mathrm{~Pa}$. Then an Ar gas flow rate of $400 \mathrm{sccm}$ was introduced into the sputtering chamber and the sputtering chamber pressure was kept at approximately 100 Pa during deposition, meanwhile, one DC power was applied to sputter concentration Pd vapor with a sputtering power of $350 \mathrm{~W}$. The Pd nanoclusters nucleated by collision process between Pd atoms vapour and Ar atoms, were squeezes into the cluster filter region and then entered into the deposition chamber $\left(5 \times 10^{-3} \mathrm{~Pa}\right)$ with a certain size ( 3.5 to $8 \mathrm{~nm}$ ) under the function of differential pressure. At last, the Pd nanocluster with narrow size distribution softly landed onto the GCP (the area was $1 \mathrm{~cm}^{2}$ ) fixed beforehand.

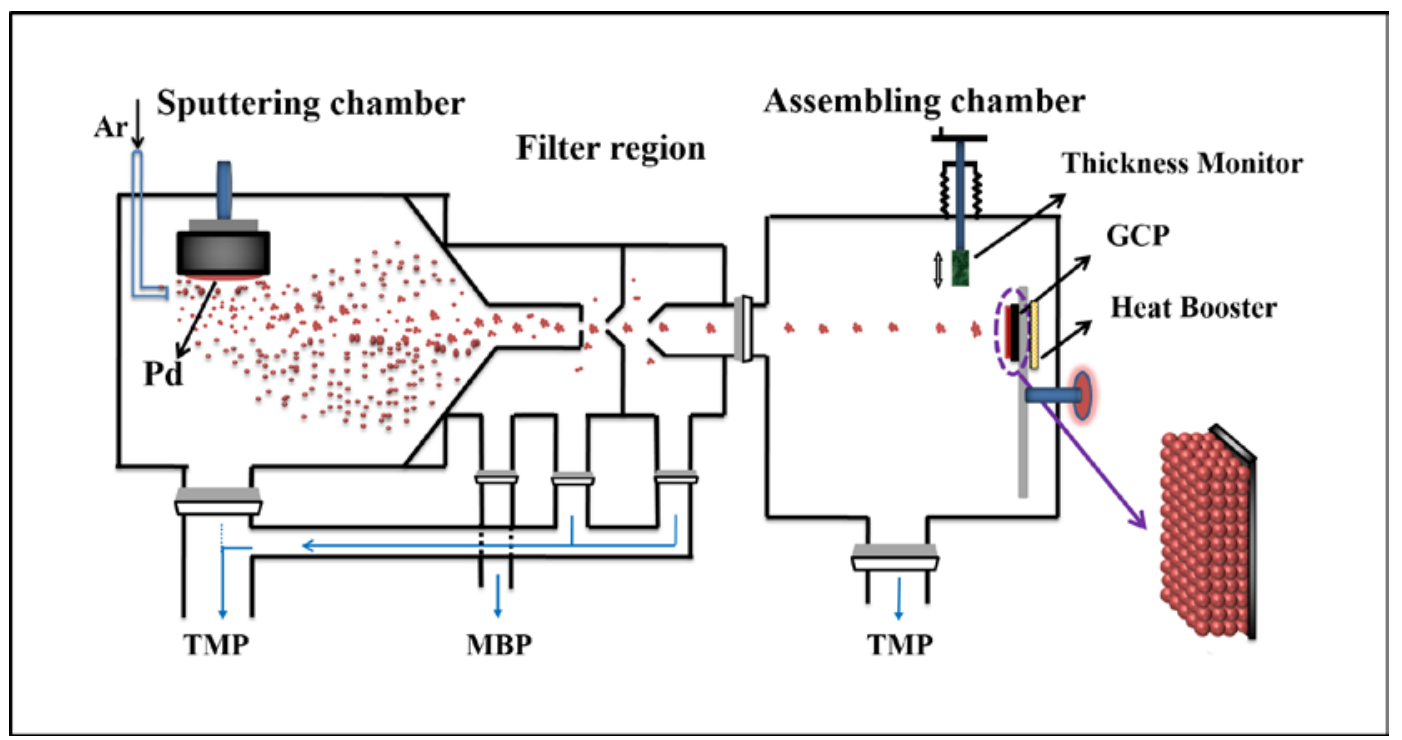

Fig. 1. The schematic diagram of Pd nanoclusters deposition process

A quartz oscillator-type thickness monitor was apply to measure the deposition rate of Pd NCs. SEM and TEM images were acquired by a scanning electron microscope (SEM, LEO-1530FE) and transmission electron microscopy (JEM-2100, $200 \mathrm{kV}$ ). And the assembled film (with Pd clusters stack thickness of about $100 \mathrm{~nm}$ ) deposited on silicon wafer and the shape and size distribution of Pd NCs (with Pd clusters stack thickness of $2.0 \sim 2.5 \mathrm{~nm}$ ) loaded on the Cu microgrid were used for SEM and TEM characterization, respectively. All of the measurements were carried out at room temperature. The crystalline structures of the Pd nanoclusters under different $T_{S}$ were investigated by XRD (Panalytical X'pert-PRO) using $\mathrm{Cu} K \alpha$ radiation at RT in the $2 \theta$ range of $15 \sim 90^{\circ}$.

An autolab $302 \mathrm{~N}$ electrochemical workstation and a conventional three-electrode test cell were used for electrochemical measurements. The counter electrode was a Pt mesh electrode of approximately $1 \mathrm{~cm}^{2}$ in area, and the reference electrode was Ag-AgCl electrode which was calibrated with respect to reversible hydrogen electrode (RHE). All potentials in this study are quoted with respect to $\mathrm{Ag} / \mathrm{AgCl}$ (0.210 V vs. SHE). The working electrode was a GCP covered with $100 \mathrm{~nm}$ thickness Pd NCs assembles on it. Before deposition, the GCPs were first polished and then cleaned with ultrasonic washer by acetone and ethanol solution in turn before adhered to substrate in deposition chamber. When cyclic voltammetry was apply to characterize samples, the electrolyte 
solution were $0.5 \mathrm{M}$ formic acid and $0.5 \mathrm{M} \mathrm{H}_{2} \mathrm{SO}_{4}$, measurement was operated at $-0.22 \sim+1.0 \mathrm{~V}$ with a scan rate of $50 \mathrm{mV} \mathrm{s}^{-1}$. The chronoamperometrys (CAs) were tested in $0.5 \mathrm{M} \mathrm{H}_{2} \mathrm{SO}_{4}+0.5 \mathrm{M}$ $\mathrm{HCOOH}$ at $0.5 \mathrm{~V}$ for $3600 \mathrm{~s}$ at RT. The electrolytes were removed oxygen by bubbling nitrogen for 30 min beforehand. Due to the clean surface of NCs, the stable CVs of our Pd catalyst could be easy to attain in 10 cycles.

\section{Results and Discussion}

Fig. 2a and $\mathrm{b}$ are the TEM and HRTEM images of the as-prepared $\mathrm{Pd}_{\mathrm{RT}}$ NCs deposited on $\mathrm{Cu}$ microgrid, respectively. It was confirmed that the spherical Pd NCs had a small size (mean diameter of $5.4 \mathrm{~nm}$ ) and a face centered cubic (fcc) structure. The SEM image shown in Fig. 2c revealed that the film was assembled by Pd NCs that were loosely packed to form a porous morphology. And each nanocluster shown in the SEM aggregated with many other NCs, so it is not easy to discern them. The XRD patterns in Fig. 2d indicated that the typical diffraction peaks located at $2 \theta$ values of $40.415^{\circ}$, $46.788^{\circ}$ and $68.423^{\circ}$ were attributed to (111), (200) and (220) planes of fcc Pd, respectively. Moreover, with the $T_{S}$ increasing, the intensity and sharpness of each typical diffraction peak became stronger, which indicated that the crystallinity of Pd NCs was enhanced and the grain size grew up due to agglomeration $[12,13]$.
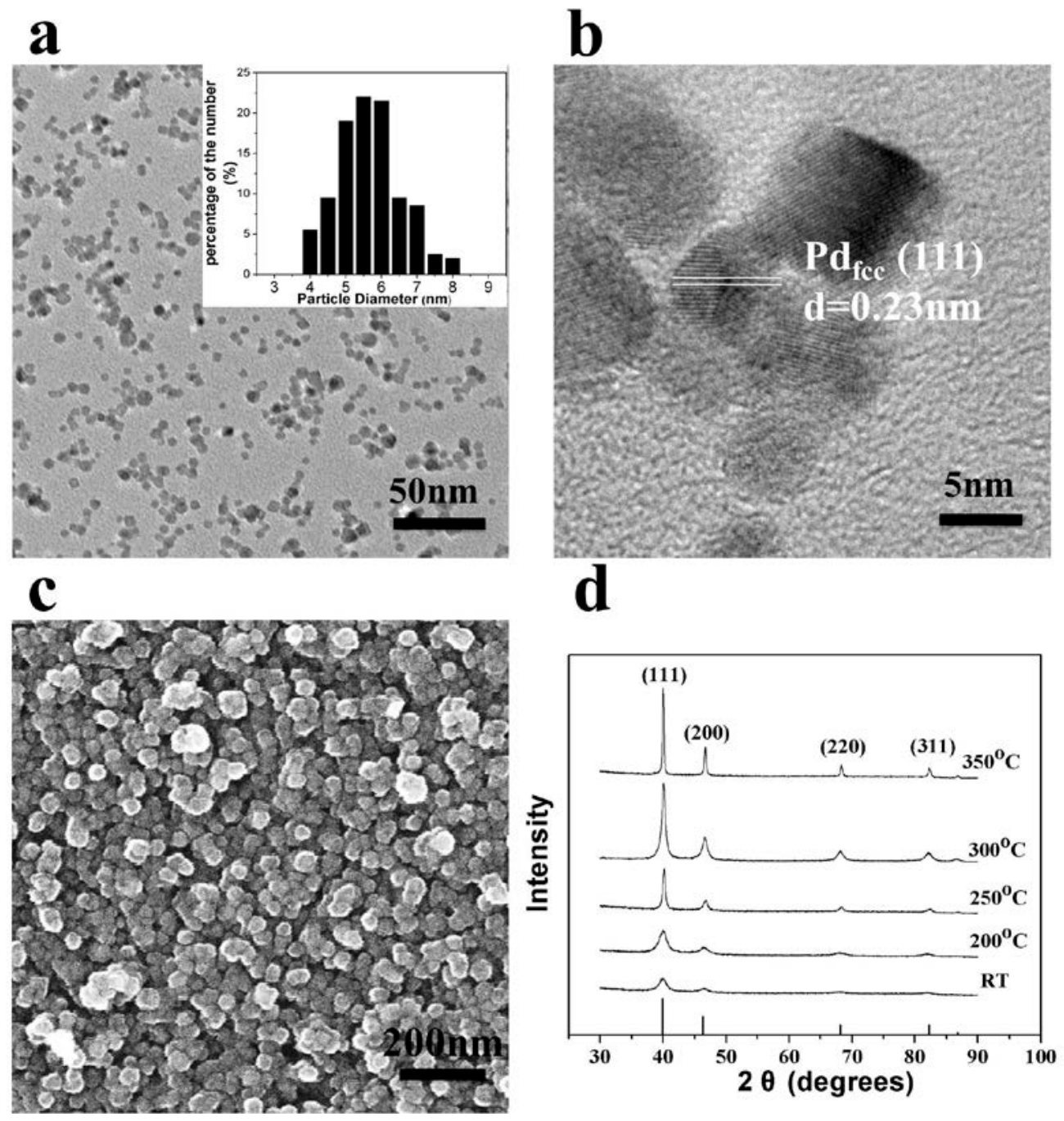

Fig. 2. TEM image with a size distribution histogram (a), HRTEM image (b) and SEM image (c) of $\mathrm{Pd}_{\mathrm{RT}}$ NCs. (d) XRD patterns of the as-prepared $\mathrm{Pd}_{\mathrm{RT}}, \mathrm{Pd}_{200}, \mathrm{Pd}_{250}, \mathrm{Pd}_{300}$ and $\mathrm{Pd}_{350} \mathrm{NCs}$. 

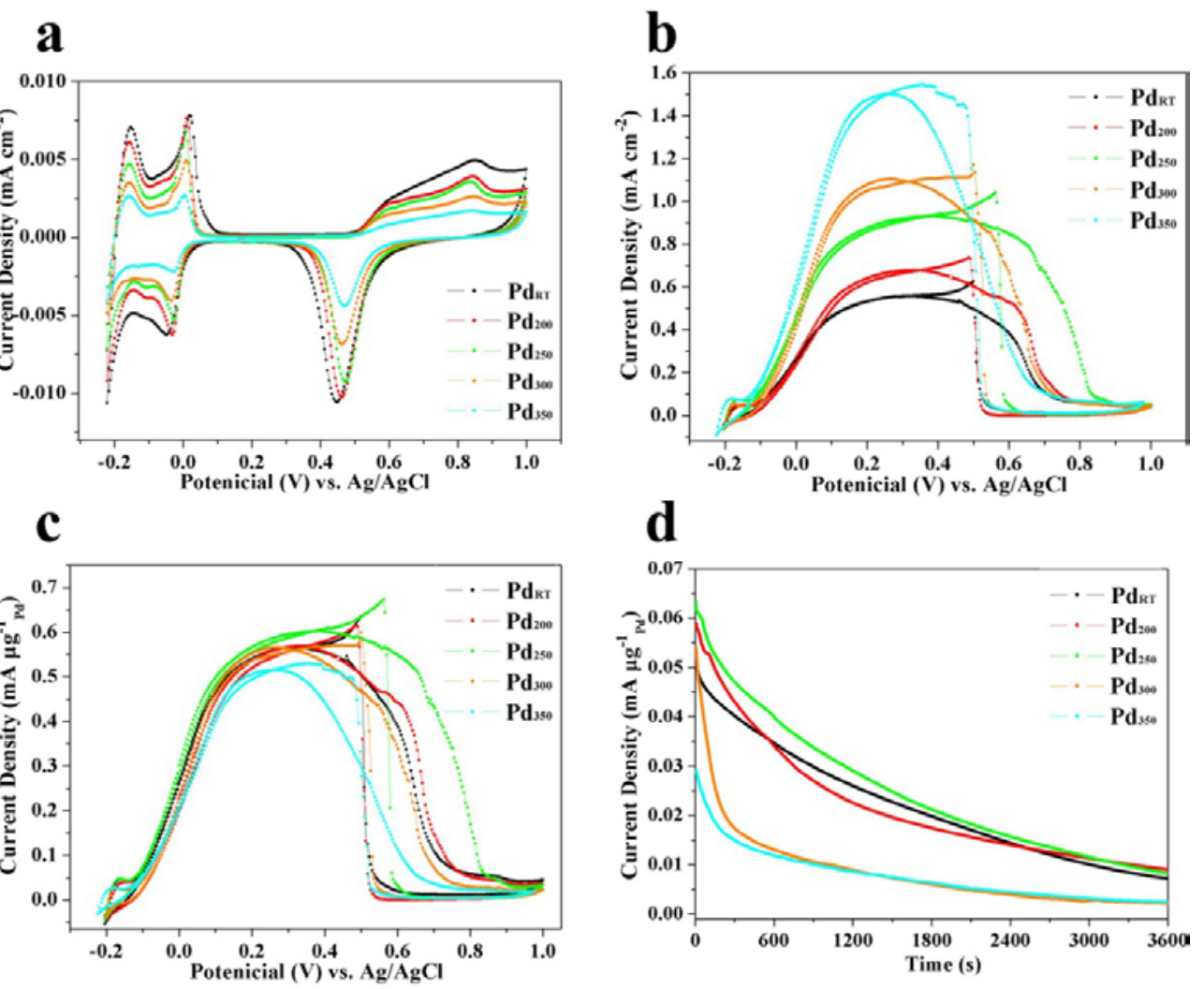

Fig. 3. CVs in $\mathrm{N}_{2}$ saturated $0.5 \mathrm{M} \mathrm{H}_{2} \mathrm{SO}_{4}$ (a), specific activities (b) and mass activities (c) in FAO in $0.5 \mathrm{M} \mathrm{H}_{2} \mathrm{SO}_{4}+0.5 \mathrm{M} \mathrm{HCOOH}$, and CAs in $0.5 \mathrm{M} \mathrm{H}_{2} \mathrm{SO}_{4}+0.5 \mathrm{M} \mathrm{HCOOH}$ at $0.5 \mathrm{~V}$ for $3600 \mathrm{~s}$ (d) of the as-prepared $\mathrm{Pd}_{\mathrm{RT}}, \mathrm{Pd}_{200}, \mathrm{Pd}_{250}, \mathrm{Pd}_{300}$ and $\mathrm{Pd}_{350} \mathrm{NCs}$.

Cyclic voltammetry of nanocluster-assembled Pd films prepared at different $T_{S}$ are exhibited in Fig. 3a, which have been normalized by the geometric area of each catalysts. As observed in this image, there are two strong peaks appeared in the forward cyclic (forward scans) process. The peaks located in the low potential region (at about $-0.22 \mathrm{~V} \sim 0.1 \mathrm{~V}$ ), can be ascribed to hydrogen adsorption and desorption process. And in the high potential region $(+0.5 \mathrm{~V})$ of the curves, the peaks was associated with Pd surface oxidation. In the cathodic scans (reverse scan) process, the peaks related to PdO reduction reaction were appeared at about $+0.45 \mathrm{~V}$. The ECSAs of each catalysts were acquired by calculating the peak area of hydrogen desorption region, which reflects the real surface area of electrodes $[14,15]$. The ECSAs were 100.0, 82.5, 64.7, 51.5 and $34.5 \mathrm{~m}^{2} \mathrm{~g}^{-1}{ }_{\mathrm{Pd}}$ for $\mathrm{Pd}_{\mathrm{RT}}, \mathrm{Pd}_{200}, \mathrm{Pd}_{250}$, $\mathrm{Pd}_{300}$ and $\mathrm{Pd}_{350}$, respectively. Due to big larger specific surface area (SSA) of Pd NCs with providing more active sites, catalysts assembled by these Pd NCs with a special spongy-network in nature was conducive to adsorption and mass transfer of FAO, and thus leaded to the high catalytic activity. However, with the $T_{S}$ increasing, the rough surface of NCs turned to be uniform and their agglomeration resulted in the diminution of SSA and ECA [16], so the ECSA value decreased.

Fig. $3 \mathrm{~b}$ and c reveal the process of FAO catalyzing reaction of the as-prepared Pd NCs, the current densities were obtained after normalizing the currents to the ECSAs (specific activities) and Pd loadings (mass activities) of each catalyst, respectively. And during the positive scans, a high $I_{p}$ could be found at near $0.35 \mathrm{~V}$ with a shoulder $I_{p}$ near $0.6 \mathrm{~V}$, which might be attributed to 2e pathway and CO pathway of FAO, respectively $[17,18]$. The first peak shows a broader contour and a much higher $I_{p}$, leaded to more formic acid molecules oxidized via the directly pathway, thus a better catalytic activity to FAO and stronger resistance performance to CO poisoning could be forecasted [19, 20]. As shown in Fig. 3b, in the positive potential scan, the specific activity for FAO on $\mathrm{Pd}_{350}$ was about $1.55 \mathrm{~mA} \mathrm{~cm}^{-2}$, which was about three times higher than that on $\operatorname{Pd}_{\mathrm{RT}}\left(0.5 \mathrm{~mA} \mathrm{~cm}^{-2}\right)$. The above results indicated that proper $T_{S}$ might improve the specific activity by optimizing the atomic arrangement to expose more active sites on the surface of Pd NCs. The mass activity in the positive-potential scan for 
FAO was shown in Fig. 3c. Interestingly, there was a slight departure from the specific activities, $\mathrm{Pd}_{250}\left(0.61 \mathrm{~mA} \mu \mathrm{g}^{-1}\right.$ Pd $)$ showed the highest mass activity instead of $\mathrm{Pd}_{350}\left(0.52 \mathrm{~mA} \mu \mathrm{g}^{-1}{ }_{\mathrm{Pd}}\right)$, which demonstrated that the utilization efficiency of Pd was reduced due to the agglomeration of NCs deposited at the overhigh $T_{S}$.

Fig. 3d shows the CAs whose rapid current decay reflected the activity and stability of each catalyst. It demonstrated that suitable $T_{S}$ could achieve a better performance with higher initial and limiting current densities, which might be partly attributed to the enhancement of adhesive strength by heating. However, above $300{ }^{\circ} \mathrm{C}$, the stability deteriorated obviously and the reason might be that the inner stress would be increased with the agglomeration being exacerbated. This perhaps made the film fracture easily, which was in accordance with the phenomenon that was observed in experimental process. These results indicate that the high catalytic activities and good stability for FAO of Pd NCs have been achieved by PVD and both of them are dependent on $T_{S}$ obviously.

\section{Summary}

The porous films assembled by clean Pd NCs with small size and fcc structure have been prepared successfully under different $T_{S}$ by employing a plasma-gas-condensation cluster deposition system. The results of CVs and CAs of the as-prepared Pd NC samples demonstrated their high overall performance of electrochemical catalysis, including the super ECAS, the significant tolerance to CO poisoning and the considerable electrochemical stability. $T_{S}$ was identified to play an important role in the catalytic activities and stability. Many further studies can be ongoing to improve the performance of Pd catalysts by means such as alloying and modifying substrate. All of the consequences signify that PVD, as a novel scheme for preparing nanoparticle catalyst assembled by metal NCs, deserves to be continued research.

\section{Acknowledgement}

This study was financially supported by the National Basic Natural Science Research Program of China (No. 2012CB933103), the National Foundation of China (No. 51171158, 51371154, 51571167 and 51301145), the Fundamental Research Funds for the Central Universities (No. 20720140547) and the Natural Science Foundation of Fujian Province of China (No. 2014J05009).

\section{References}

[1] Chen, P. Holt-Hindle, Chem. Rev. 110 (2010) 3767-3804.

[2] Rice, S. Ha, R.I. Masel, P. Waszczuk, A. Wieckowski, T. Barnard, J. Power Sources 111 (2002) 83-89.

[3] J.D. Lovic, A.V. Tripkovic, S.L. Gojkovic, K.D. Popovic, D.V. Tripkovic, P. Olszewski, A. Kowal, J. Electroanal. Chem. 581 (2005) 294-302.

[4] Wang, J. Power Sources 152 (2005) 1-15.

[5] X.M. Chen, G.H. Wu, J.M. Chen, X. Chen, Z.X. Xie, X.R. Wang, J. Am. Chem. Soc. 133 (2011) 3693-3695.

[6] V. Mazumder, Y. Lee, S. Sun, Adv. Funct. Mater. 20 (2010) 1224-1231.

[7] Y. Xiong, Y. Xia, Adv. Mater. 19 (2007) 3385-3391.

[8] Z.L. Liu, L. Hong, M.P. Tham, T.H. Lim, H.X. Jiang, J. Power Sources 161 (2006) 831-835.

[9] V. Mazumder, S.H. Sun, J. Am. Chem. Soc. 131 (2009) 4588-4589.

[10] K.J.J. Mayrhofer, M. Arenz, B.B. Blizanac, V. Stamenkovic, P.N. Ross, N.M. Markovic, Electrochim. Acta 50 (2005) 5144-5154 
[11] D.L. Peng, K. Sumiyama, K. Kumagai, T. Yamabuchi, D. Kobayashi, T. Hihara, J. Mater. Res. (2008) 189-197.

[12] L.S. Wang, R.T. Wen,Y. Chen, G.H. Yue, D.L. Peng, T. Hihara, Appl. Phys. A 103 (2011) 1015-1020.

[13] D.L. Peng, K. Sumiyama, K. Suzuki, J. Alloy Comp. 259 ( 1997) 1-6.

[14] M. Grden, A. Piascik, Z. Koczorowski, J. Czerwinski, Electroanal. Chem. 532 (2002) 35-42.

[15] C.Y. Du, M. Chen,W.G. Wang, G.P. Yin, P.F. Shi, Electrochem. Commun. 12 (2010) 843-846.

[16] Y.Z. Lu, W. Chen, J. Phys. Chem. C 114 (2010) 21190-21200.

[17] V. Mazumder, M. Chi, M.N. Mankin,Y. Liu, D.H. Sun, K.L. More, S.H. Sun, Nano Lett. 12 (2012) 1102-1106.

[18] Z. Liu, L. Hong, M.P. Tham, T.H. Lim, H.X. Jiang, J. Power Sources 161 (2006) 831-835.

[19] Du, M. Chen, W. Wang, G. Yin, P. Shi, Electrochem. Commun. 12 (2010) 843-846.

[20] J. Sun, Y. Wang, C. Zhang, T. Kou, Z. Zhang, Electrochem. Commun. 21 (2012) 42-45. 